\title{
BMJ Exposure to selective serotonin reuptake OPen inhibitors and the risk of congenital malformations: a nationwide cohort study
}

\author{
Espen Jimenez-Solem, ${ }^{1,2}$ Jon Traerup Andersen, ${ }^{1,2}$ Morten Petersen, ${ }^{1,2}$ \\ Kasper Broedbaek, ${ }^{1,2}$ Jonas Krogh Jensen, ${ }^{3}$ Shoaib Afzal, ${ }^{1,2}$ Gunnar H Gislason, ${ }^{3}$ \\ Christian Torp-Pedersen, ${ }^{3,4}$ Henrik Enghusen Poulsen ${ }^{1,2,4}$
}

To cite: Jimenez-Solem E, Andersen JT, Petersen M, et al. Exposure to selective serotonin reuptake inhibitors and the risk of congenital malformations: a nationwide cohort study. BMJ Open 2012;2:e001148. doi:10. 1136/bmjopen-2012-001148

- Prepublication history and additional materials for this paper are available online. To view these files please visit the journal online (http://dx. doi.org/10.1136/ bmjopen-2012-001148).

Received 11 March 2012 Accepted 11 May 2012

This final article is available for use under the terms of the Creative Commons Attribution Non-Commercial 2.0 Licence; see http://bmjopen.bmj.com

${ }^{1}$ Laboratory of Clinical Pharmacology,

Rigshospitalet, Copenhagen, Denmark

${ }^{2}$ Department of Clinical Pharmacology, Bispebjerg Hospital, Copenhagen, Denmark

${ }^{3}$ Department of Cardiology, Gentofte Hospital, Copenhagen, Denmark ${ }^{4}$ Faculty of Health Sciences University of Copenhagen, Copenhagen, Denmark

Correspondence to Espen Jimenez-Solem; espen.jimenez.solem@rh. regionh.dk

\section{ABSTRACT}

Objectives: To analyse the relation between selective serotonin reuptake inhibitor (SSRI) use and major congenital malformations, with focus on malformations of the heart.

Design: Register-based retrospective nationwide cohort study, using the Danish Medical Birth Registry. Setting: Denmark.

Participants: Pregnant women in Denmark between 1997 and 2009 and their offspring.

Primary outcome measures: For each SSRI, ORs for major congenital malformations were estimated using multivariable logistic regression models for women exposed to an SSRI during the first trimester and for women with paused exposure during pregnancy.

Results: The authors identified 848786 pregnancies; 4183 were exposed to an SSRI throughout the first trimester and 806 pregnancies paused exposure during pregnancy. Risks of congenital malformations of the heart were similar for pregnancies exposed to an SSRI throughout the first trimester, adjusted OR 2.01 $(95 \% \mathrm{Cl} 1.60$ to 2.53$)$, and for pregnancies with paused SSRI treatment during pregnancy, adjusted OR 1.85 (95\% Cl 1.07 to 3.20$)$, p value for difference: 0.94. The authors found similar increased risks of specific congenital malformations of the heart for the individual SSRIs. Furthermore, the authors found no association with dosage.

Conclusions: The apparent association between SSR use and congenital malformations of the heart may be confounded by indications. The moderate absolute risk increase combined with uncertainty for causality still requires the risk versus benefit to be evaluated in each individual case.

\section{INTRODUCTION}

Depression is common during pregnancy and up to $15 \%$ of pregnant women suffer from depression or depressive symptoms. ${ }^{12}$ The most used pharmacological treatment

\section{ARTICLE SUMMARY}

Article focus

- Relationship between SSRIs and congenital malformations.

- Focus on malformations of the heart.

- Focus on women with paused treatment during pregnancy.

Key messages

- Risks of congenital malformations of the heart are increased for infants whose mothers were exposed to an SSRI during the first trimester.

- Risks of congenital malformations of the heart are not different for pregnancies exposed during the first trimester as for pregnancies with paused treatment during pregnancy.

- The found risk increases are moderate in absolute terms.

Strengths and limitations of this study

- Observational study-no causal relations.

- Nationwide study, including all live births in the study period.

- Register-based study—no recall bias.

for pregnant women is selective serotonin reuptake inhibitors (SSRIs). ${ }^{3-6}$ Treatment with SSRIs during pregnancy in Denmark has doubled over a short span of time with $1.4 \%$ of pregnancies treated in 2004 compared with $2.4 \%$ in 2007. This rapid increase has also been observed in other countries where the proportion of pregnant women treated with an SSRI is reported to be even higher than in Denmark. ${ }^{4-8}$ Several studies have analysed the consequences of this treatment on pregnancy outcomes and indicated an increased risk of congenital malformations ${ }^{9}{ }^{10}$ and more notably heart defects. ${ }^{11-21}$ However, the data are conflicting ${ }^{11} \quad 13 \quad 16-18 \quad 22-32$ and studies including up to a million pregnancies indicate little risk of congenital malformations. ${ }^{11} 16183031$ None of these studies have 
successfully managed to differentiate between the consequences of the drugs themselves and the underlying disease. Given the uncertainty of safety and the common use, we performed a nationwide study of the relationship between SSRI use and congenital malformations with focus on congenital heart defects and comparison with paused use during pregnancy to account for special characteristics of women using antidepressants.

\section{MATERIALS AND METHODS}

Through the Danish Medical Birth Registry, we identified all pregnancies in Denmark between 1997 and 2009. Their drug redemptions were identified using the Register of Medicinal Product Statistics. We calculated the associations between exposure to SSRIs and congenital malformations using multivariable logistic regression adjusted for maternal characteristics.

\section{Study population}

At birth, all Danish citizens are given a unique permanent identification number, ${ }^{33}$ which enable personalised information to be linked across databases. Using the Danish Medical Birth Registry, we identified 854008 births between 1997 and 2009. We excluded 5222 records with missing data on date of birth and pregnancy length. The final cohort consisted of 848786 pregnancies (99.4\% of all pregnancies). The Danish Medical Birth Registry includes data on all births in Denmark since $1973^{34}$ and the following information is contained: unique identification numbers of mother and child as well recorded time of gestation, which is based on last menstrual period and ultrasound estimates. We obtained medical treatment from the Danish Register of Medicinal Product Statistics, which, since 1995, has recorded drugs dispensed from Danish pharmacies. Registration is close to perfect due to partial reimbursement by healthcare authorities. ${ }^{35}$ For this reason, direct importing by patients is nearly non-existent. The register contains type of drug (International Anatomical Therapeutic Coding (ATC)), date of redemption, quantity dispensed and strength. ${ }^{36}$ Information on smoking was gathered from the Danish Medical Birth Registry. Individual information on household income and highest attained level of education was gathered from Statistics Denmark. ${ }^{37}$

\section{Outcome measures}

Congenital malformations were identified through the Danish National Hospital Register. ${ }^{38}$ We identified children with congenital malformation within 1 year of birth and the corresponding grouping according to the European Surveillance of Congenital Anomalies classification system guide $1.3 .^{39}$

\section{Identification of exposure}

Exposure to the following SSRIs (ATC codes) was identified in the present study: fluoxetine (N06AB03), citalopram (N06AB04), paroxetine (N06AB05), sertraline (N06AB06) and escitalopram (N06AB10). Other SSRIs were not included because of low incidence of use $(\mathrm{n}<50)$.

SSRI prescriptions redeemed during the study period were identified through the Register of Medicinal Product Statistics. Using the date of prescription, strength and number of tablets prescribed, we performed an estimation of exposure periods and dosages of the individual SSRIs. We calculated dosage as the average of up to seven prescriptions based on the standard dose of the individual antidepressant. Calculation of drug exposure periods using this method has been described previously. ${ }^{40}$

We identified all pregnancies exposed to an SSRI during the first trimester with a continuous exposure before pregnancy by defining it as exposure between at least 1 month before conception and day 84 of pregnancy (last day of the first trimester). Women changing exposure to another SSRI during the first trimester were not included in the study $(\mathrm{n}=646)$. In order to address a possible confounding by indication, we compared our cohort exposed during the first trimester with a control cohort comprised women with paused exposure during pregnancy. We defined women with paused exposure as exposure to an SSRI 3-12 months before conception and 1-12 months after giving birth but with no exposure to an SSRI between 3 months before conception to 1 month after giving birth. In addition, they had to be exposed to the same individual SSRI before and after pregnancy to ensure comparability with women exposed during the first trimester.

We divided the study population into pregnancies exposed to high or low SSRI dose based on the recommended daily dose values of the individual SSRIs during pregnancy. Doses over the following cut-off values were considered as high doses: $20 \mathrm{mg}$ for citalopram, $10 \mathrm{mg}$ for escitalopram, $20 \mathrm{mg}$ for fluoxetine, $20 \mathrm{mg}$ for paroxetine and $50 \mathrm{mg}$ for sertraline.

\section{Statistical analysis}

Baseline characteristics were compared with $\chi^{2}$ tests for categorical variables. Risks of malformations were examined with linear logistic regression models. In multivariable analyses, we included the mother's age divided into five categories: $<20,20-25,25-30,30-35$, $>35$ years $(0 \%$ missing values). Annual gross household income was divided into quartiles $(<1 \%$ missing values). The highest obtained level of education attained was divided into three groups: low, medium and high, resulting in $4.3 \%$ missing values. The number of prior births (parity), including stillbirths, was divided into three classes: one, two, and more than two births $(<1 \%$ missing values). Year of conception was divided into five categories (1995-1997, 1998-2000, 2001-2003, 2004-2006 and 2007-2009). Smoking was divided into five categories according to the number of daily cigarette: $0,1-10,11-20,>20$ and unknown $(<1 \%$ missing values). Body mass index (BMI) was divided into four 
groups $(<21,21-25,26-30,>30)$. Information on BMI was only available from 1 January 2004 and includes $7 \%$ missing values in the period 2004-2009 (table 1). Records with missing values in the above-mentioned categories were not included in the multivariable analyses.

\section{Ethics}

The present study has been approved by the Danish Data Protection Agency (No. 2008-41-2517). Retrospective register studies do not require ethical permission in Denmark. Our findings are reported according to strengthening the reporting of observational studies in epidemiology (STROBE). ${ }^{41}$

\section{RESULTS}

We identified 4183 pregnancies exposed to an SSRI throughout the first trimester, 806 pregnancies with paused exposure and 843797 pregnancies not exposed to an SSRI. Eighty-three per cent of pregnancies exposed to an SSRI throughout the first trimester went on to redeem, a prescription of an SSRI during the third trimester. Table 1 shows the basic characteristics for women exposed to an SSRI and for unexposed women. Table 2 presents the association between exposure to SSRIs and major congenital malformation with more than 10 cases and specific septal congenital defects of the heart. For information on risks associated with the

Table 1 Maternal characteristics of women exposed to an SSRI and unexposed

\begin{tabular}{|c|c|c|c|c|c|}
\hline \multirow[b]{3}{*}{ Characteristic } & \multicolumn{3}{|l|}{ Exposed to SSRIs } & & \\
\hline & \multirow{2}{*}{$\begin{array}{l}\text { First trimester }(n=4183) \\
n(\%)\end{array}$} & \multicolumn{2}{|c|}{$\begin{array}{l}\text { Paused during } \\
\text { pregnancy }(n=806)\end{array}$} & \multicolumn{2}{|c|}{ Unexposed $(n=843797)$} \\
\hline & & n (\%) & p Value ${ }^{*}$ & n (\%) & p Value* \\
\hline Education & & & $<0.01$ & & $<0.001$ \\
\hline Short & $1731(41.38)$ & $372(46.15)$ & & 280447 (33.24) & \\
\hline Medium & $1119(26.75)$ & 225 (27.92) & & 254194 (30.13) & \\
\hline Long & $1262(30.17)$ & 193 (23.95) & & 272380 (32.28) & \\
\hline Missing values & $71(1.70)$ & $16(1.99)$ & & $36776(4.36)$ & \\
\hline Annual household income & & & 0.12 & & $<0.001$ \\
\hline$<\$ 58335$ & $1320(31.56)$ & 264 (32.75) & & 210290 (24.92) & \\
\hline$\$ 58335-\$ 93656$ & $1101(26.32)$ & $222(27.54)$ & & $212110(25.14)$ & \\
\hline$\$ 93656-\$ 119082$ & $906(21.66)$ & 185 (22.95) & & 211436 (25.06) & \\
\hline$\$ 119082$ or greater & $856(20.46)$ & 135 (16.75) & & 207247 (24.56) & \\
\hline Missing values & $0(-)$ & $0(-)$ & & $2714(0.32)$ & \\
\hline Age (years) & & & $<0.001$ & & $<0.001$ \\
\hline$<20$ & $70(1.67)$ & $20(2.48)$ & & $23324(2.76)$ & \\
\hline $21-25$ & 555 (13.27) & $122(15.14)$ & & 129059 (15.30) & \\
\hline $26-30$ & $1364(32.61)$ & 269 (33.37) & & 318664 (37.77) & \\
\hline $31-35$ & $1423(34.02)$ & $295(36.60)$ & & 268959 (31.87) & \\
\hline$>35$ & 771 (18.43) & $100(12.41)$ & & 102791 (12.18) & \\
\hline Missing values & $0(-)$ & $0(-)$ & & $0(-)$ & \\
\hline Parity & & & $<0.001$ & & $<0.001$ \\
\hline 1 & $1983(47.41)$ & 282 (34.99) & & 368168 (43.63) & \\
\hline 2 & $1320(31.56)$ & $310(38.46)$ & & 308992 (36.62) & \\
\hline$>2$ & 833 (19.91) & $208(25.81)$ & & 162030 (19.20) & \\
\hline Missing values & 47 (1.12) & $6(0.74)$ & & $4607(0.55)$ & \\
\hline Daily cigarettes & & & 0.53 & & $<0.001$ \\
\hline 0 & $2810(67.18)$ & $532(66)$ & & 660888 (78.32) & \\
\hline $1-10$ & $1049(25.08)$ & $211(26.18)$ & & 128269 (15.2) & \\
\hline $11-20$ & $66(1.58)$ & $11(1.36)$ & & $5294(0.63)$ & \\
\hline$>20$ & $138(3.30)$ & 34 (4.22) & & 20967 (2.48) & \\
\hline No information & $118(2.82)$ & $18(2.23)$ & & 27580 (3.27) & \\
\hline Missing values & $2(0.05)$ & $0(-)$ & & 799 (0.09) & \\
\hline Pre-pregnancy BMI & & & 0.89 & & $<0.001$ \\
\hline$<21$ & 391 (12.23) & $66(12.60)$ & & 53500 (13.95) & \\
\hline $21-25$ & $1393(43.59)$ & $233(44.47)$ & & 186428 (48.62) & \\
\hline $26-30$ & 705 (22.06) & 117 (22.33) & & 74673 (19.48) & \\
\hline$>30$ & 493 (15.43) & 74 (14.12) & & 41652 (10.86) & \\
\hline Missing values & $214(6.70)$ & $35(6.68)$ & & $27161(7.08)$ & \\
\hline
\end{tabular}


Table 2 Risk of congenital malformations among women exposed to an SSRI versus women with no exposure

\begin{tabular}{|c|c|c|c|c|c|c|}
\hline \multirow[b]{3}{*}{ Outcome } & \multicolumn{5}{|c|}{ Exposed to any SSRI } & \multirow{3}{*}{$\begin{array}{l}\text { No exposure } \\
(n=843797) \\
n(\%)\end{array}$} \\
\hline & \multicolumn{2}{|c|}{ First trimester $(n=4183)$} & \multicolumn{2}{|c|}{$\begin{array}{l}\text { Paused during pregnancy } \\
(n=806)\end{array}$} & \multirow[b]{2}{*}{ p Value* } & \\
\hline & n (\%) & OR $(95 \% \mathrm{Cl}) \dagger$ & n (\%) & OR $(95 \% \mathrm{Cl}) \dagger$ & & \\
\hline Major malformations & $208(4.97)$ & $1.33(1.16$ to 1.53$)$ & $36(4.47)$ & $1.27(0.91$ to 1.78$)$ & 0.90 & 29703 (3.52) \\
\hline $\begin{array}{l}\text { Congenital malformations } \\
\text { of the heart }\end{array}$ & $77(1.84)$ & 2.01 (1.60 to 2.53 ) & $13(1.61)$ & 1.85 (1.07 to 3.20$)$ & 0.94 & 7755 (0.92) \\
\hline Septal defects & $49(1.17)$ & 2.04 (1.53 to 2.72$)$ & $11(1.36)$ & $2.56(1.41$ to 4.64$)$ & 0.35 & $4826(0.57)$ \\
\hline Ventricular septal defects & $21(0.50)$ & $1.62(1.05$ to 2.50$)$ & $9(1.12)$ & 3.74 (1.93 to 7.23$)$ & 0.97 & $2803(0.33)$ \\
\hline Atrial septal defects & $34(0.81)$ & 2.60 (1.84 to 3.68$)$ & $6(0.74)$ & 2.61 (1.17 to 5.84$)$ & 0.74 & $2490(0.30)$ \\
\hline $\begin{array}{l}\text { Congenital malformations } \\
\text { of the digestive system }\end{array}$ & $13(0.31)$ & 1.80 (1.04 to 3.12$)$ & $1(0.12)$ & 0.75 (0.11 to 5.35$)$ & 0.59 & $1545(0.18)$ \\
\hline $\begin{array}{l}\text { Congenital malformations } \\
\text { of the internal urinary system }\end{array}$ & $11(0.26)$ & $0.84(0.45$ to 1.57$)$ & - & - & - & $2333(0.28)$ \\
\hline $\begin{array}{l}\text { Congenital malformations } \\
\text { of the external genital organs }\end{array}$ & $19(0.45)$ & 1.55 (0.99 to 2.44$)$ & $2(0.25)$ & 0.89 (0.22 to 3.59$)$ & 0.46 & $2504(0.30)$ \\
\hline $\begin{array}{l}\text { Congenital malformations } \\
\text { of the limbs }\end{array}$ & $53(1.27)$ & $0.93(0.71$ to 1.23$)$ & $14(1.74)$ & 1.37 (0.80 to 2.32$)$ & 0.18 & $11785(1.40)$ \\
\hline
\end{tabular}

remaining congenital malformations, please refer to supplement A.

\section{First trimester exposure to any SSRI versus no exposure}

The rate of major congenital malformations among pregnancies exposed to any SSRI throughout the first trimester was 50 per 1000 pregnancies compared with 35 per 1000 unexposed pregnancies (figure 1). We found an association between SSRI exposure and major congenital malformations, adjusted OR 1.33 (95\% CI 1.16 to 1.53 ) (table 2).

When analysing the association between exposure to any SSRI and the different major malformations according to the European Surveillance of Congenital Anomalies classification, we found a statistically significant association between exposure to an SSRI and congenital malformations of the heart, adjusted OR 2.01 (95\% CI 1.60 to 2.53 ), and congenital malformations of the digestive system, adjusted OR 1.80 (95\% CI 1.04 to 3.12 ), but not the remaining major congenital malformations (table 2).

\section{Paused exposure versus unexposed}

The rate of major congenital malformations among pregnancies with paused exposure during pregnancy was 45 per 1000 pregnancies (figure 1). The risk of any major malformation for women with paused exposure to an SSRI during pregnancy was, adjusted OR 1.27 (95\% CI 0.91 to 1.78 ), compared with unexposed pregnancies. When estimating the risk of specific major congenital malformations, we found that paused exposure was associated with congenital malformations of the heart, adjusted OR 1.85 (95\% CI 1.07 to 3.20) (table 2). We performed additional analyses increasing the drug-free period before pregnancy to 6 and 9 months and found similar estimates as for the group pausing exposure 3 months before conception (supplement $\mathrm{C}$ ).

\section{Other analyses}

Exposure to individual SSRIS

We found a significant association between major congenital malformations and exposure to citalopram, adjusted OR 1.51 (95\% CI 1.21 to 1.87$)$, and sertraline, adjusted OR 1.41 (95\% CI 1.03 to 1.92). Furthermore, we found an association between congenital malformations of the heart and exposure to citalopram, adjusted OR 1.91 (95\% CI 1.31 to 2.77), fluoxetine, adjusted OR 2.05 (95\% CI 1.27 to 3.31 ), and sertraline, adjusted OR $2.73(95 \%$ CI 1.75 to 4.26). Associations for the remaining major congenital malformations are presented in supplement A.

\section{Specific heart defects}

We performed a subanalysis of the specific congenital septal defects of the heart and their association with exposure to SSRIs and found an association between exposure to any SSRI and septal heart defects, adjusted OR 2.04 (95\% CI 1.53 to 2.72) (table 2). Specifically, ventricular septal defects and atrial septal defects were associated with an increased risk. Increased risk of congenital septal defects was also found for pregnancies with paused exposure, adjusted OR 2.56 (95\% CI 1.41 to 4.64) (table 2).

For the individual SSRIs, we found an association between exposure to all SSRIs, except for escitalopram, and atrial septal defects. Ventricular septal defects was 
Figure 1 Rates per 1000 pregnancies of major congenital malformations for infants exposed to selective serotonin reuptake inhibitors in utero. Figure shows number of infants diagnosed with a major malformation per 1000 births. Rates are shown with $95 \%$ Cls.

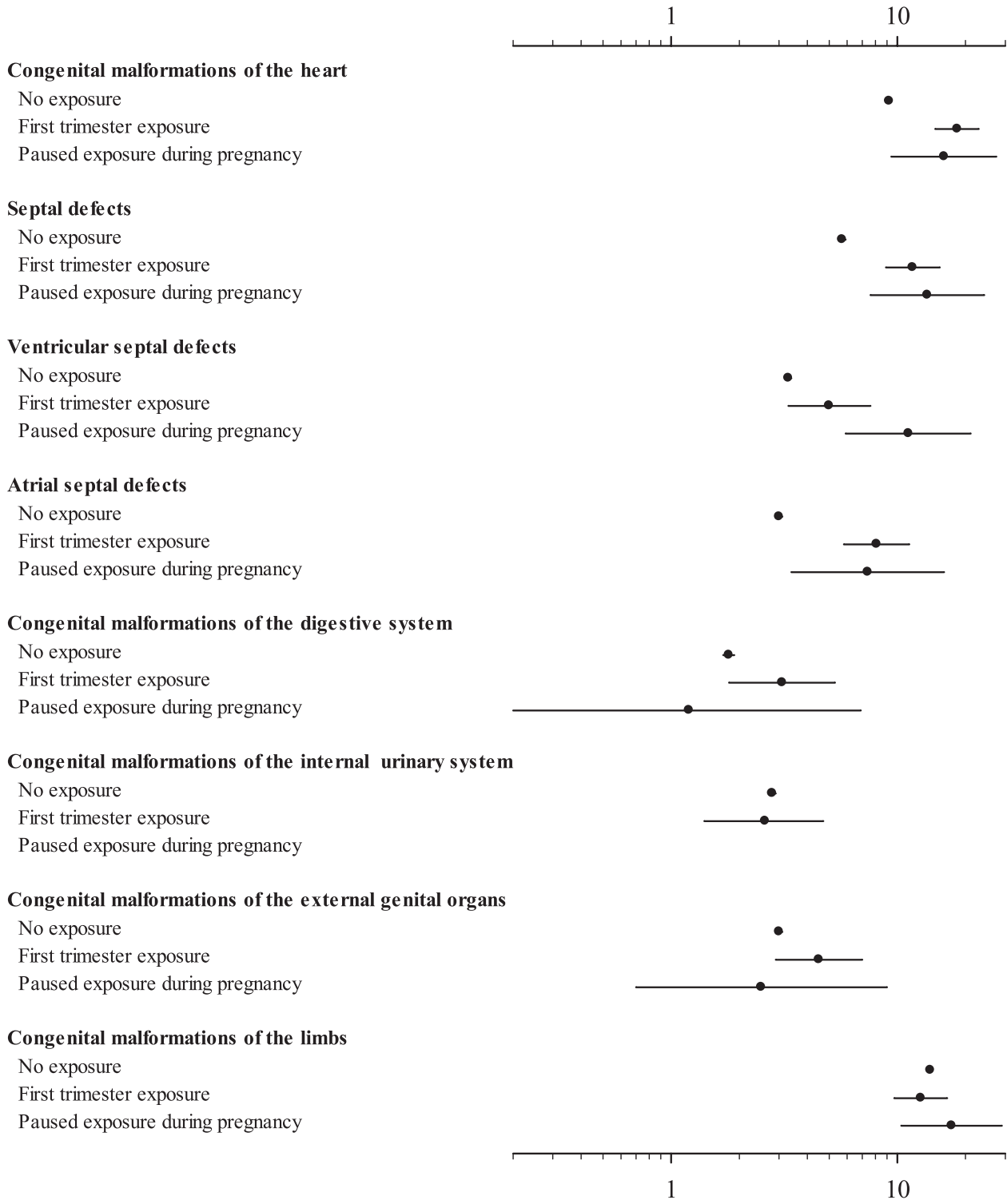

Congenital malformations of the he art

No exposure

First trimester exposure

First trimester exposure

entricular septal defects

No exposure

First trimester exposure

only associated with exposure to sertraline, adjusted OR 3.60 (95\% CI 1.86 to 6.96$)$, and not the remaining individual SSRIs (supplement A).

\section{Other congenital defects}

Studies have reported a possible association between exposure to an SSRI during pregnancy and omphalocele, anencephaly and craniosynostosis. ${ }^{9}{ }^{10}$ We found an association for exposure to an SSRI in the first trimester and craniosynostosis $(\mathrm{n}=9)$, adjusted OR $1.94(95 \%$ CI 1.00 to 3.76 ), but not for omphalocele or anencephaly. For pregnancies with paused exposure, we found an association with craniosynostosis $(\mathrm{n}=3)$, adjusted OR 3.64 (95\% CI 1.17 to 11.34 ).

\section{Dosage}

We found an adjusted OR for major malformations: OR 1.39 (95\% CI 1.14 to 1.68) for low-dose exposure and 1.27 (95\% CI 1.03 to 1.56) for high-dose exposure ( $\mathrm{p}$ for difference $=0.29$ ).
For the individual major malformations, we found similar associations for pregnancies exposed to low dose and pregnancies exposed to high dose, as for the whole cohort (table 3). Analysing the effect of dose as a continuous variable yielded no dose-response association.

\section{Additional adjustments}

In order to identify possible unaccounted confounders, we performed additional multivariable analyses including co-medication (psycholeptics; ATC code A05, and antidiebetics; ATC code A10) as independent variables in our model. The results showed no considerable change in the estimates or their level of significance compared with our primary analysis (supplement B).

When including BMI as an independent variable in our multivariable model, we found the same statistically significant associations for exposure to any SSRI or individual SSRIs and the specific congenital malformations as our multivariable model not adjusted for BMI. Information on BMI was only available for pregnancies 
Table 3 ORs and 95\% Cls for association between congenital malformations among women exposed to low-dose and highdose SSRI during pregnancy

\begin{tabular}{|c|c|c|c|c|c|}
\hline \multirow[b]{2}{*}{ Outcome } & \multicolumn{2}{|c|}{ Low-dose SSRI $(n=2588)$} & \multicolumn{2}{|c|}{ High-dose SSRI $(n=1603)$} & \multirow[b]{2}{*}{ p Value $\uparrow$} \\
\hline & n (\%) & OR $(95 \% \mathrm{Cl})^{*}$ & n (\%) & OR $(95 \% \mathrm{Cl})^{\star}$ & \\
\hline Major malformations & $121(4.68)$ & $1.26(1.05$ to 1.51$)$ & $87(5.43)$ & $1.44(1.15$ to 1.79$)$ & 0.29 \\
\hline $\begin{array}{l}\text { Congenital malformations } \\
\text { of the heart }\end{array}$ & $44(1.70)$ & 1.83 (1.35 to 2.48$)$ & $33(2.06)$ & 2.26 (1.60 to 3.19$)$ & 0.41 \\
\hline $\begin{array}{l}\text { Congenital malformations } \\
\text { of the digestive system }\end{array}$ & $8(0.31)$ & $1.78(0.89$ to 3.58$)$ & $5(0.31)$ & $1.80(0.75$ to 4.35$)$ & 0.99 \\
\hline $\begin{array}{l}\text { Congenital malformations } \\
\text { of the internal urinary system }\end{array}$ & $6(0.23)$ & $0.82(0.37$ to 1.83$)$ & $5(0.31)$ & 0.88 (0.33 to 2.34$)$ & 0.63 \\
\hline $\begin{array}{l}\text { Congenital malformations } \\
\text { of the external genital organs }\end{array}$ & $10(0.39)$ & 1.32 (0.71 to 2.46$)$ & $9(0.56)$ & 1.91 (0.99 to 3.68$)$ & 0.42 \\
\hline $\begin{array}{l}\text { Congenital malformations } \\
\text { of the limbs }\end{array}$ & $33(1.28)$ & $0.94(0.67$ to 1.33$)$ & $20(1.25)$ & 0.91 (0.59 to 1.42$)$ & 0.93 \\
\hline
\end{tabular}

after 1 January 2004, which reduced our cohort to 3196 pregnancies exposed to an SSRI and 383946 with no exposure.

\section{Non-SSRI antidepressants}

We found no association between congenital malformations and exposure to non-SSRI antidepressants: tricyclic antidepressants (ATC N06AA, n=223) and other antidepressants (ATC N06AX, n=831), adjusted OR $1.04(95 \%$ CI 0.53 to 2.03) and adjusted OR 0.70 (95\% CI 0.47 to 1.05$)$, respectively. We found no associations with congenital malformations of the heart, adjusted OR 1.33 (95\% CI 0.42 to 4.15 ) for tricyclic antidepressants and adjusted OR 0.99 (95\% CI 0.51 to 1.91) for other antidepressants.

\section{DISCUSSION}

We performed a retrospective nationwide cohort study analysing the association between redemption of an SSRI during pregnancy and major congenital malformations. We found an association between exposure to an SSRI during the first trimester and major congenital malformations, more specifically, congenital malformations of the heart (ventricular septal defects and atrial septal defects) and congenital malformations of the digestive system. Furthermore, we found an association between women with paused SSRI exposure during pregnancy and congenital malformations of the heart. Based on findings described in the published literature, we will centre the following discussion on major congenital malformations and congenital malformations of the heart for pregnancies exposed to SSRIs.

Our study's results are in accordance with two earlier Danish studies ${ }^{20} 42$ based on cohorts comprising only part of the entire nation. A third Danish nationwide study by Pedersen et $a l^{17}$ found an increased estimate for major congenital malformations and congenital malformations of the heart, though not statistically significant, in the studied period 1996-2004. The number of exposed women in their study was 1370, compared with ours 4183, which could explain why our estimates reached statistical significance. The study concludes that there is a class effect of SSRIs on heart defects.

Several studies have not found an association between exposure to any SSRI and major malformations overall. $^{11} 131618$ 22-32 We find that some of these study are not comparable to ours because most of them are case-control studies and with cohorts much smaller than ours. ${ }^{13}$ 22-29 31 Five of the studies are though similar to ours, based on nationwide cohorts and national registers, and cohort sizes comparable to ours. Four are based on Swedish data and are successive updates $^{16183031}$ and one on Finnish data. ${ }^{11}$

The latest update of Swedish data found an increased risk of cardiovascular congenital malformations for pregnancies exposed to paroxetine but not for the remaining individual SSRIs or SSRI as a group. ${ }^{18}$ Information on SSRI exposure was partly based on antenatal interviews, which could, although unlikely, give rise to recall bias. Furthermore, their analyses were adjusted for BMI. Adjusting our multivariable analysis for BMI had little effect on the estimates.

The Finnish study found an increased risk of ventricular septal defects for pregnancies exposed to fluoxetine but not for the remaining individual SSRIs or SSRI as a group. ${ }^{11}$ The study is completely based on national registers, like our study. Exposure was though defined as redemption of at least one prescription between 1 month before pregnancy and the end of the first trimester. This could underestimate the number of exposed women if prescriptions for an SSRI were redeemed just before and after this chosen period. This could indicate continuous exposure during the first trimester and push estimates towards unity and, in theory, explain the lack of association with major congenital malformations and specifically atrial septal defects.

None of the above-mentioned studies assessed the risk of congenital malformations for women with paused 
exposure during pregnancy and thereby addressing the possibility of confounding by indication. Furthermore, neither the Swedish nor the Finnish studies adjusted their analyses for socioeconomic factors, which in our study are unevenly distributed between our exposed and unexposed population. However, additional adjusted analyses not including socioeconomic factors yielded estimates and CIs that did not differ from our fully adjusted analysis (data not shown). Importantly, we believe that there are socio-demographic differences between the populations included in these Scandinavian studies compared with ours. Although Denmark resembles both Sweden and Finland, differences in culture and healthcare policies could account for the discrepancies in our results. Discrepancies between published studies could also be due to the low number of cases, where each case can have a significant effect on the estimate.

Congenital malformations of the heart have been associated with exposure to SSRIs in some studies, ${ }^{10-12} 15-18273142$ in contrast to studies not identifying this association. ${ }^{9} 131926$ Our analyses showed an increased risk of congenital heart defects for the individual SSRIs. Risks of atrial septal defects were furthermore associated with exposure to all individual SSRIs, except for escitalopram. The lack of statistical significance with escitalopram exposure could be due to low statistical power. We found the same increased risks for heart defects for those with paused exposure during pregnancy, which strengthens the assumption of confounding by indication.

Although statistically significant, the increased risks associated with SSRI exposure are small in absolute terms. For example, the populations' background risk of atrial septal defects is $0.26 \%$, and even if we estimate a twofold risk increase associated with exposure to any SSRI, the risk of giving birth to a child with this congenital malformation would be approximately five cases for every 1000 births (figure 1).

\section{STRENGTHS AND LIMITATIONS}

The main weakness is the observational design. We had access to important covariates but it cannot be excluded that unaccounted confounder explain the results. Our study could furthermore be affected by a possible detection bias. Pregnant women exposed to SSRIs are reported to have increased rates of observed malformations due to increased rates of ultrasound examinations compared with women not treated with SSRIs. ${ }^{43}$ In contrast, detection of a malformation during an ultrasound examination could lead to pregnancy termination and thereby decreased rates of malformations among the SSRI exposed. On the other hand, infants of women redeeming prescriptions for SSRIs undergo, in the first year of life, approximately twice as many echocardiograms compared with infants of unexposed women. ${ }^{43}$ More frequent echocardiograms could increase the risk of heart defect detection and give rise to information bias (diagnostic suspicion bias). This bias could partly explain our findings. On the other hand, more frequent echocardiograms could indicate a more severe symptomatology among the exposed children due to an unaccounted factor.

Importantly, information on indication for elective termination of pregnancies was not available in our databases. If pregnant women exposed to an SSRI had a higher rate of provoked abortions due to severe malformations, it could mask a possible teratogenic effect of the drugs.

There is a possibility that we have overestimated SSRI treatment periods since we cannot adjust for lack of compliance or the patients' intention of commencing a treatment shortly after drug redemption. However, it has been estimated that the majority of redeemed prescriptions by pregnant women are taken, ${ }^{44}$ and compliance in Denmark has been estimated to be $80 \%$ for antidepressant treatment during pregnancy. ${ }^{45}$ Furthermore, an overestimation of treatment periods would bias our estimates towards unity. We performed additional analyses defining exposure as redemption of two SSRI prescriptions during pregnancy. The results of these analyses, which are not presented, yielded the same statistically significant association as our primary analyses. Furthermore, we cannot rule out that women defined as pausing their treatment 3 months before conception were misclassified and had treatment periods reaching into pregnancy. We addressed this issue by increasing the washout period before pregnancy and estimating risks for women pausing treatment 6 and 9 months before conception. The results showed similar estimates as for women pausing exposure 3 months before pregnancy (supplement $\mathrm{C}$ ).

A main strength is the complete national design including nearly all births in Denmark and the mothers' drug redemptions in the study period. The Register of Medicinal Product Statistics includes approximately $97.5 \%$ of all redeemed prescriptions. ${ }^{35}$ Danish pharmacies are, by law, required to register all redeemed prescriptions as part of the national healthcare reimbursement scheme. All prescriptions have been redeemed and paid for, which increases the probability of exposure. Recall bias is eliminated since information was recorded prospectively and not based on questionnaires or interviews. Furthermore, to our knowledge, this is the first study to address a possible confounding by indication by assessing risks associated with paused exposure to SSRIs during pregnancy.

\section{Conclusions}

Our study shows with high confidence a relationship between exposure to an SSRI during the first trimester and risk of congenital malformations of the heart. In addition, we found a nearly identical risk for women who used an SSRI before and after pregnancy but discontinued use during pregnancy. We find both associations strong enough to conclude that risks related to SSRI use during the first trimester are a result of an unaccounted 
confounder associated to the redemption of an SSRI prescription. This was sustained by the lack of relationship between dose and risk. A possible explanation could be information bias because children of women redeeming an SSRI are more likely to undergo an echocardiogram during the first year of life. However, based on our study's design, we cannot rule out an actual causal relationship between redemption of an SSRI and congenital malformations. We found no relationship with non-SSRI antidepressants, which may indicate a particular risk with SSRIs, but which may also be explained by lack of power.

We therefore conclude that the apparent association between SSRI use and congenital malformations of the heart may be confounded by indications. The moderate absolute risk increase combined with uncertainty for causality still requires the risk versus benefit to be evaluated in each individual case.

Acknowledgements The authors wish to acknowledge the help of Klaus Kähler Holst, Department of Biostatistics at the University of Copenhagen, for contributing with statistical help.

Contributors EJ-S, JTA and HEP conceptualised the study and MP, KB, JKJ, $\mathrm{SA}, \mathrm{GHG}$ and $\mathrm{CT}-\mathrm{P}$ assisted with the study design. EJ-S preformed the analyses and JTA, MP, KB, CT-P and HEP assisted in the interpretation. EJ-S, JTA, MP, KB, JKJ, SA, GHG, CT-P and HEP wrote and revised the article, as well as designed figures. All authors approved the final version to be published.

Funding The research project was partially sponsored by the Capital Region of Copenhagen and the Danish Agency for Science, Technology and Innovation. Coverage of PhD enrolment fees.

Competing interests All authors declare no support from any organisation for the submitted work; no financial relationships with any organisations that might have an interest in the submitted work in the previous 3 years; no other relationships or activities that could appear to have influenced the submitted work.

Ethics approval The present study has been approved by the Danish Data Protection Agency (No. 2008-41-2517). Retrospective register studies do not require ethical permission in Denmark.

Provenance and peer review Not commissioned; externally peer reviewed.

Data sharing statement No additional data were available.

\section{REFERENCES}

1. Bennett HA, Einarson A, Taddio A, et al. Prevalence of depression during pregnancy: systematic review. Obstet Gynecol 2004;103:698-709.

2. Chatillon $\mathrm{O}$, Even $\mathrm{C}$. [Antepartum depression: prevalence, diagnosis and treatment] (In French). Encephale 2010;36:443-51.

3. Ververs T, Kaasenbrood H, Visser G, et al. Prevalence and patterns of antidepressant drug use during pregnancy. Eur J Clin Pharmacol 2006:62:863-70.

4. Cooper WO, Willy ME, Pont SJ, et al. Increasing use of antidepressants in pregnancy. Am J Obstet Gynecol 2007;196:544-5.

5. Andrade SE, Raebel MA, Brown J, et al. Use of antidepressant medications during pregnancy: a multisite study. $\mathrm{Am} \mathrm{J}$ Obstet Gynecol 2008;198:194-5.

6. Alwan S, Reefhuis J, Rasmussen SA, et al; Prevention study TNBD. Patterns of antidepressant medication use among pregnant women in a United States population. J Clin Pharmacol 2011;51:264-70.

7. Bakker MK, Kolling P, van den Berg PB, et al. Increase in use of selective serotonin reuptake inhibitors in pregnancy during the last decade, a population-based cohort study from the Netherlands. $\mathrm{Br} \mathrm{J}$ Clin Pharmacol 2008;65:600-6.

8. Wichman $\mathrm{CL}$, Fothergill $\mathrm{A}$, Moore $\mathrm{KM}$, et al. Recent trends in selective serotonin reuptake inhibitor use in pregnancy. J Clin Psychopharmacol 2008;28:714-16.
9. Alwan S, Reefhuis J, Rasmussen SA, et al. Use of selective serotonin-reuptake inhibitors in pregnancy and the risk of birth defects. N Engl J Med 2007;356:2684-92.

10. Louik $\mathrm{C}$, Lin $\mathrm{AE}$, Werler MM, et al. First-trimester use of selective serotonin-reuptake inhibitors and the risk of birth defects. $N$ Engl J Med 2007;356:2675-83.

11. Malm H, Artama M, Gissler M, et al. Selective serotonin reuptake inhibitors and risk for major congenital anomalies. Obstet Gynecol 2011;118:111-20.

12. Bakker MK, Kerstjens-Frederikse WS, Buys $\mathrm{CH}$, et al. First-trimester use of paroxetine and congenital heart defects: a population-based case-control study. Birth Defects Res A Clin Mol Teratol 2010;88:94-100.

13. Berard A, Ramos E, Rey E, et al. First trimester exposure to paroxetine and risk of cardiac malformations in infants: the importance of dosage. Birth Defects Res B Dev Reprod Toxicol 2007:80:18-27.

14. Cole JA, Ephross SA, Cosmatos IS, et al. Paroxetine in the first trimester and the prevalence of congenital malformations. Pharmacoepidemiol Drug Saf 2007;16:1075-85.

15. Diav-Citrin O, Shechtman S, Weinbaum D, et al. Paroxetine and fluoxetine in pregnancy: a prospective, multicentre, controlled, observational study. Br J Clin Pharmacol 2008:66:695-705.

16. Kallen BA, Otterblad OP. Maternal use of selective serotonin re-uptake inhibitors in early pregnancy and infant congenital malformations. Birth Defects Res A Clin Mol Teratol 2007;79:301-8.

17. Pedersen LH, Henriksen TB, Vestergaard M, et al. Selective serotonin reuptake inhibitors in pregnancy and congenital malformations: population based cohort study. BMJ 2009;339:b3569.

18. Reis M, Kallen B. Delivery outcome after maternal use of antidepressant drugs in pregnancy: an update using Swedish data. Psychol Med 2010;40:1723-33.

19. Wichman CL, Moore KM, Lang TR, et al. Congenital heart disease associated with selective serotonin reuptake inhibitor use during pregnancy. Mayo Clinic Proc 2009;84:23-7.

20. Wogelius P, Norgaard M, Gislum M, et al. Maternal use of selective serotonin reuptake inhibitors and risk of congenital malformations. Epidemiology 2006;17:701-4.

21. Wurst KE, Poole C, Ephross SA, et al. First trimester paroxetine use and the prevalence of congenital, specifically cardiac, defects: a meta-analysis of epidemiological studies. Birth Defects Res A Clin Mol Teratol 2010;88:159-70.

22. Malm H, Klaukka T, Neuvonen PJ. Risks associated with selective serotonin reuptake inhibitors in pregnancy. Obstet Gynecol 2005;106:1289-96.

23. Kulin NA, Pastuszak A, Sage SR, et al. Pregnancy outcome following maternal use of the new selective serotonin reuptake inhibitors: a prospective controlled multicenter study. JAMA 1998;279:609-10.

24. Ramos E, St-Andre M, Rey E, et al. Duration of antidepressant use during pregnancy and risk of major congenital malformations. $\mathrm{Br} \mathrm{J}$ Psychiatry 2008;192:344-50.

25. Einarson A, Choi J, Einarson TR, et al. Incidence of major malformations in infants following antidepressant exposure in pregnancy: results of a large prospective cohort study. Can $J$ Psychiatry 2009;54:242-6.

26. Davis RL, Rubanowice D, McPhillips $\mathrm{H}$, et al. Risks of congenital malformations and perinatal events among infants exposed to antidepressant medications during pregnancy. Pharmacoepidemiol Drug Saf 2007;16:1086-94.

27. Oberlander TF, Warburton W, Misri S, et al. Major congenital malformations following prenatal exposure to serotonin reuptake inhibitors and benzodiazepines using population-based health data. Birth Defects Res B Dev Reprod Toxicol 2008;83:68-76.

28. Simon GE, Cunningham ML, Davis RL. Outcomes of prenatal antidepressant exposure. Am J Psychiatry 2002;159:2055-61.

29. Wen SW, Yang Q, Garner P, et al. Selective serotonin reuptake inhibitors and adverse pregnancy outcomes. Am J Obstet Gynecol 2006;194:961-6.

30. Ericson A, Kallen B, Wiholm B. Delivery outcome after the use of antidepressants in early pregnancy. Eur $\mathrm{J}$ Clin Pharmacol 1999;55:503-8.

31. Kallen B, Otterblad Olausson P. Antidepressant drugs during pregnancy and infant congenital heart defect. Reprod Toxicol 2006;21:221-2.

32. Lennestal RM, Kallen B. Delivery outcome in relation to maternal use of some recently introduced antidepressants. J Clin Psychopharmacol 2007;27:607-13.

33. Pedersen CB, Gotzsche H, Moller JO, et al. The Danish Civil Registration System. A cohort of eight million persons. Dan Med Bull 2006; 53:441-9.

34. Knudsen LB, Olsen J. The Danish medical birth registry. Dan Med Bull 1998;45:320-3. 
35. Sorensen HT, Hansen I, Ejlersen E, et al. Identification of patients treated with strong analgesics: an assessment of two Danish information systems with respect to epidemiological research. J Med Syst 1996;20:57-65.

36. Gaist D, Sorensen HT, Hallas J. The Danish prescription registries. Dan Med Bull 1997;44:445-8.

37. Statistics Denmark. Containing Detailed Statistical Information on the Danish Society. http://www.dst.dk/en (accessed Mar 2012).

38. Andersen TF, Madsen M, Jorgensen J, et al. The Danish National Hospital Register. A valuable source of data for modern health sciences. Dan Med Bull 1999;46:263-8.

39. European Surveillance of Congenital Anomalies. EUROCAT Guide 1.3 and Reference Documents. Newtownabbey Co Antrim. University of Ulster, 2005. http://www.eurocat-network.eu/content/EUROCATGuide-1.3.pdf (accessed Mar 2012).

40. Fosbol EL, Gislason GH, Jacobsen S, et al. The pattern of use of nonsteroidal anti-inflammatory drugs (NSAIDs) from 1997 to 2005: a nationwide study on 4.6 million people. Pharmacoepidemiol Drug Saf 2008; 17:822-33.
41. von Elm E, Altman DG, Egger M, et al. The strengthening the reporting of observational studies in epidemiology (STROBE) statement: guidelines for reporting observational studies. Lancet 2007;370:1453-7.

42. Kornum JB, Nielsen RB, Pedersen L, et al. Use of selective serotonin-reuptake inhibitors during early pregnancy and risk of congenital malformations: updated analysis. Clin Epidemiol 2010;2:29-36.

43. Bar-Oz B, Einarson $\mathrm{T}$, Einarson $\mathrm{A}$, et al. Paroxetine and congenital malformations: meta-Analysis and consideration of potential confounding factors. Clin Ther 2007;29:918-26.

44. de Jong van den Berg LT, Feenstra N, Sorensen HT, et al. Improvement of drug exposure data in a registration of congenital anomalies. Pilot-study: pharmacist and mother as sources for drug exposure data during pregnancy. EuroMAP Group. European Medicine and Pregnancy Group. Teratology 1999;60:33-6.

45. Olesen C, Sondergaard C, Thrane N, et al. Do pregnant women report use of dispensed medications? Epidemiology 2001;12:497-501. 


\section{Correction}

Jimenez-Solem E, Andersen JT, Petersen M, et al. Exposure to selective serotonin reuptake inhibitors and the risk of congenital malformations: a nationwide cohort study. BMJ Open 2012;2:e001148. Data supplement 1 (online supplement A) for this paper has been corrected since it was first published. The correct table for online supplement A is now available online at http://dx.doi.org/10.1136/bmjopen-2012-001148.

BMJ Open 2013;3:e001148corr1. doi:10.1136/bmjopen-2012-001148corr1 